\title{
Syzygium aromaticum essential oil prevents halitosis caused by oral bacteria Streptococcus sanguinis
}

\author{
1, *Yanti, ${ }^{2}$ Juniardi, S. and ${ }^{2}$ Lay, B.W. \\ ${ }^{I}$ Department of Food Technology, Faculty of Biotechnology, Atma Jaya Catholic University of Indonesia, \\ Jakarta 12930, Indonesia \\ ${ }^{2}$ Department of Biology, Faculty of Biotechnology, Atma Jaya Catholic University of Indonesia, Jakarta \\ 12930, Indonesia
}

\section{Article history: \\ Received: 4 May 2019 \\ Received in revised form: 7 \\ June 2019 \\ Accepted: 16 June 2019 \\ Available Online: 28 June 2019}

Keywords:

Anti-halitosis effect,

Clove bud,

Essential oil,

Streptococcus sanguinis,

Syzygium aromaticum

DOI:

https://doi.org/10.26656/fr.2017.3(6).175

\begin{abstract}
Halitosis is caused by oral bacteria including Streptococcus sanguinis in mouth producing volatile sulphur compounds (VSCs), such as hydrogen sulfide, ethyl mercaptan, and methyl mercaptan which have pungent odor. Bacteria producing sulphur compounds produce oral biofilms as the accumulation of caries promotion. Caries is caused by the acid produced by oral bacteria that lead to tooth demineralization in low $\mathrm{pH}$ condition. Clove bud (Syzygium aromaticum), known as endogenous spice in Indonesia, has been traditionally used for centuries for treatment of periondal diseases. In this study, we extracted essential oil from Syzygium aromaticum (SAEO), identifed for its major essential oils by pyrolysis gas chromatograpy mass spectrometry (py-GC/MS), determined its antihalitosis efficacy on preventing and eradicating $S$. sanguinis oral biofilms, inhibiting VSCs and acid production in vitro. Chromatogram profile showed that SAEO contained major eugenol (22.10\%) and aceteugenol (13.31\%). For antibiofilm effect toward oral bacteria $S$. sanguinis, SAEO at 40 and $60 \mu \mathrm{g} / \mathrm{mL}$ effectively prevented biofilm formation up to $60 \%$ and removed the existed biofilms up to $50 \%$. SAEO at $60 \mu \mathrm{g} / \mathrm{mL}$ also demonstrated a significant inhibition on VSCs production (up to 58\%) and acid produced by $S$. sanguinis by increasing the terminal $\mathrm{pH}$ from 5.66 to 6.30 . These data suggest that SAEO could be applied for a promising candidate for developing oral care functional products for management of halitosis.
\end{abstract}

\section{Introduction}

Halitosis is widely known as bad breath and is caused by volatile sulphur compounds (VSCs) which mostly produced by anaerobic Gram-negative bacteria, such as Phorphyromonas gingivalis, Weisselia cibaria, Treponema denticola, Provetella intermedia, and Fusobacterium nucleatum. Various volatile compounds like hydrogen sulfide, methyl mercaptan, putrescine, indole, cadaverine and propionate are known to have pungent odor. Volatile compounds are byproducts of amino acid or sugar metabolism. The substrate used for the volatile compounds in mouth came from host component such as food particles, mucosal cells, blood and precipitated saliva (Marawar et al., 2012). Hydrogen sulfide is a volatile product formed by cysteine desulfhydrase and uses cysteine as the primary substrate. Methyl mercaptan is produced by methionine $\gamma$-lyase with methionine as a primary substrate (Thorn and John, 2012). Hydrogen sulfide and methyl mercaptan are known as the major VSCs produced by Gram-negative bacteria and act as an indicator for halitosis (Kang et al., 2006).

Gram-positive bacteria also have a major role in halitosis by promoting caries formation on the tooth, followed by the formation of biofilm and production of acid which accelerates tooth enamel demineralization. The biofilm is recognized as a suitable environment for VSCs producing bacteria to grow (Duarte et al., 2006; Kang et al., 2006). Gram-positive bacteria, such as Streptococcus mutans and S. sanguinis produce biofilm for attachment on the tooth surface. S. sanguinis is one of the initial bacteria to make tooth surface environment suitable for other bacteria to colonize. S. sanguinis competes with other bacteria to colonize the tooth surface by producing hydrogen peroxidase to inhibit other bacteria growth (Kreth et al., 2012). Initial attachment for $S$. sanguinis on tooth surface used hydrophobic interaction and attachment on epithelial cells using anchoring adhesin protein produces by the srtA gene (Percival et al., 2006). The biofilm formed by 
S. sanguinis is also a problem because the acid byproducts are contained in the biofilm and make the $\mathrm{pH}-$ condition on tooth surface become acid (Paes Leme et al., 2008). The acid condition makes tooth calcium easier to be diluted by water, the process is also known as demineralization. $S$. sanguinis is a natural flora in the oral environment, but it may cause endocarditis if the bacteria get into the bloodstream (Duarte et al., 2006). The most abundant substance in $S$. sanguinis biofilm is glucan which is synthesized by glucosyltransferase (GTF). S. sanguinis produces two kinds of GTF including GtfB and GtfP. GtfB produces insoluble glucan with $\alpha-1,3$ bond. GtfB is a virulence factor for dental caries because glucan becomes the adherence place for other bacteria (Yamaguchi et al., 2006).

Syzygium aromaticum, known as clove bud or cengkeh (in Indonesian), is a native spice grouped in Myrtaceae family from Molucca Islands in Indonesia and has been traditionally used for the treatment of toothache and root canal infection, as well as oral anesthetic purpose for management of periodontal diseases. The parts of $S$. aromaticum plant such as the stems, flower buds, and leaves have been reported to contain high essential oils particularly eugenol and acetyl eugenol (Rahim and Khan, 2006). Eugenol is a monoterpene with a molecular weight of $164 \mathrm{~g} / \mathrm{mol}$ and has been reported to have antimicrobial, antimutagenic, and antiinflammatory effects (Pal et al., 2010).

Several recent studies related to the use of $S$. aromaticum extract and its essential oil content for the treatment of periodontal diseases including halitosis have been reported. A cross-sectional survey by Akkaoui and Ennibi (2017) reported that there were 23 medicinal plants including clove commonly used by Moroccan herbalists for the treatment of halitosis. A study by Kaur and Chandrul (2017) showed that the main component of clove oil was eugenol, with $\beta$-caryophyllene and eugenyl acetate; but the contents of essential oils in cloves were found to be various depending on their anatomic and geographical origins. Another study by Pulikottil and Nath (2015) showed that clove and its derivatives exerted dual anti-plaque and anti-inflammatory effects for the treatment of periodontal disease. Fahimi and Naseri (2015) also stated that halitosis is a well-known disorder in Iranian traditional medicines (ITM), and the use of 14 herbal plants and their mixtures in ITM has been scientifically proven for their biological activities relating to anti-halitosis effect. Therefore, in this study, we investigated whether essential oils isolated from the flower buds of $S$. aromaticum had anti-halitosis activity toward $S$. sanguinis oral bacteria by preventing the formation of biofilms and eradicating the existed biofilms, inhibiting total VSCs production, and reducing acid production in vitro.

\section{Materials and methods}

\subsection{Materials}

The dried flower buds of $S$. aromaticum were purchased from traditional market in Jakarta (Indonesia) and stored in a voucher specimen (code: LY05) at Faculty of Biotechnology, Atma Jaya Catholic University of Indonesia, Jakarta (Indonesia).

\subsection{Extraction and identification of essential oil from $S$. aromaticum flower bud}

Essential oil from the dried S. aromaticum flower bud was extracted in n-hexane using maceration (Guan et al., 2007). The dried flower buds were powdered by grinding and a $20 \mathrm{~g}$ of dried powder was extracted in 200 $\mathrm{mL}$ of $\mathrm{n}$-hexane, followed by maceration for $48 \mathrm{hrs}$ at room temperature. Essential oil and solvent were separated by evaporation at $350 \mathrm{mbar}$ and $50^{\circ} \mathrm{C}$, followed by drying the essential oil in fume hood overnight. S. aromaticum essential oil (SAEO) was obtained and stored in room temperature. Chemical compounds in SAEO was analysed by pyrolysis-gas chromatography-mass Spectrometry (py-GC/MS) according to the method of Kang et al. (2006). A $0.5 \mathrm{~g}$ of sample was injected to the capillary column (Phase Rtx5MS) with a film thickness of $60 \mathrm{~m} \times 0.25 \mathrm{~mm}$, ID. Pyrolysis temperature was set to $280^{\circ} \mathrm{C}$ using helium as a carrier gas.

\subsection{Antibiofilm assay}

Antibiofilm activity of SAEO was assayed for prevention and eradication effects using $S$. sanguinis (ATCC 5513) biofilm model according to the modified method of Yanti et al. (2008). S. sanguinis was inoculated in Brain Heart Infusion (BHI) media or BHIA (BHI supplemented with $1.5 \%$ of bacteriological agar at $37^{\circ} \mathrm{C}$ for $24 \mathrm{hrs}$ aerobically. The media were centrifuged in $4500 \times g$ for 5 mins. The supernatant was discarded and then the pellet was resuspended using adherence buffer $\left(\mathrm{KH}_{2} \mathrm{PO}_{4} 10 \mathrm{mM}, \mathrm{KCl} 50 \mathrm{mM}, \mathrm{CaCl}_{2} 1 \mathrm{mM}\right.$, and $\left.\mathrm{MgCl}_{2} 0.1 \mathrm{mM}\right)$.

For prevention assay, the 96-well plate was coated with $150 \mu \mathrm{l}$ artificial saliva $\left(1 \% \mathrm{CMC}, \mathrm{KH}_{2} \mathrm{PO}_{4} 10 \mathrm{mM}\right.$, $\mathrm{KCl} 50 \mathrm{mM}, \mathrm{CaCl}_{2} 1 \mathrm{mM}$, and $\mathrm{MgCl}_{2} 0.1 \mathrm{mM}$ ) and $50 \mu \mathrm{l}$ SAEO at various concentrations $(20-100 \mu \mathrm{g} / \mathrm{mL})$. Chlorhexidine at $20 \mu \mathrm{g} / \mathrm{mL}$ was used as a reference standard. The plate was dried at $37^{\circ} \mathrm{C}$ overnight. For treatment, a $20 \mu \mathrm{L} S$. sanguinis culture $\left(1 \times 10^{6} \mathrm{CFU} /\right.$ $\mathrm{mL})$ and $180 \mu \mathrm{L}$ BHI media supplemented with $3 \%$ sucrose (BHIS) were added into each well. The negative control (untreated) was BHIS medium and the cell 
suspension without sample, and the blank control contained only BHIS medium. The plate was incubated at $37^{\circ} \mathrm{C}$ for $24 \mathrm{hrs}$. The well was gently washed using PBS to discard the planktonic cells. The well was dried in room temperature for $1 \mathrm{hrs}$. The biofilm formed at the bottom of the well was dyed using $110 \mu \mathrm{L}$ crystal violet $0.4 \%$ for 30 mins. The well was destained using $200 \mu \mathrm{L}$ ethanol absolute. A $100 \mu \mathrm{L}$ ethanol absolute was transferred to the new well and the absorbance was measured at $596 \mathrm{~nm}$ using microplate reader. The percentage of inhibition was calculated using the equation:

$\left(1-\mathrm{A}_{596}\right.$ of sample/ $\mathrm{A}_{596}$ of the untreated control) $\mathrm{x} 100$.

For eradication assay, the 96-well plate was coated with $150 \mu \mathrm{L}$ artificial saliva. The plate was dried at $37^{\circ} \mathrm{C}$ overnight. After drying, a $20 \mu \mathrm{L}$ S. sanguinis culture $(1 \mathrm{x}$ $10^{6} \mathrm{CFU} / \mathrm{mL}$ ) and $180 \mu \mathrm{L}$ BHIS were added into each well. The plate was incubated at $37^{\circ} \mathrm{C}$ for $24 \mathrm{hrs}$. After the biofilm formed, a $50 \mu \mathrm{L}$ SAEO at various concentrations $(20-100 \mu \mathrm{g} / \mathrm{mL})$ was added to each well for $1 \mathrm{hr}$. Chlorhexidine at $20 \mu \mathrm{g} / \mathrm{mL}$ was used as a reference standard. For the negative control (untreated), the same steps were taken except that BHIS medium $(200 \mu \mathrm{L})$ was used without sample or addition of cell culture. The well was gently washed using PBS to discard the planktonic cells in the well. The well was dried in room temperature for $1 \mathrm{hr}$. The biofilm formed at the bottom of the well was dyed using $110 \mu \mathrm{L}$ crystal violet $0.4 \%$ for 30 mins. The well was destained using $200 \mu \mathrm{L}$ ethanol absolute. A $100 \mu \mathrm{L}$ ethanol absolute was transferred to the new well and the absorbance was measured at $596 \mathrm{~nm}$ using microplate reader. The remained biofilm cells were quantified as described previously. SAEO activity was defined as the percentage absorbance of the biofilm remaining after sample treatment in comparison with the untreated control.

\subsection{Inhibition on $S$. sanguinis volatile sulphur compounds production}

The assay was carried out according to the method of
Cord-Ruwisch (1985). S. sanguinis culture $\left(1 \times 10^{6} \mathrm{CFU} /\right.$ $\mathrm{mL})$ was growth in BHI media in the glass tube, followed by the addition of $\mathrm{CuSO}_{4} 0.2 \%$, methionine $0.5 \%$, and SAEO at various concentrations $(20-100 \mu \mathrm{g} /$ $\mathrm{ml}$ ). Tubes were incubated at $37^{\circ} \mathrm{C}$ for $24 \mathrm{hrs}$ to measure the production of $\mathrm{H}_{2} \mathrm{~S}$. The formation of $\mathrm{H}_{2} \mathrm{~S}$ resulted in a brown precipitate that was measured at $480 \mathrm{~nm}$ using a spectrophotometer.

\subsection{Inhibition on $S$. sanguinis acid production}

The assay was done to determine the changes in the production of acid by using a $\mathrm{pH}$ meter (Percival et al., 2006). S. sanguinis bacterial cultures were grown on BHI medium at $37^{\circ} \mathrm{C}$ for $24 \mathrm{hrs}$, followed by centrifugation at $4500 \times g$ for 5 mins. Pellets were taken and rinsed with a saline solution containing $\mathrm{KCl} 200 \mathrm{mM}$ and $\mathrm{MgCl}_{2} 20$ $\mathrm{mM}$. Bacteria that have been rinsed were resuspended in $5 \mathrm{~mL}$ of saline solution. One $\mathrm{ml}$ of solution was transferred into a beaker containing $100 \mathrm{mM}$ sucrose solution and SAEO at various concentrations (20-100 $\mu \mathrm{g} / \mathrm{mL}$ ), then the $\mathrm{pH}$ change was measured for 30 mins and the $\mathrm{pH}$ value was recorded every minute.

\subsection{Statistical analysis}

Statistical analysis was used to determine the accuracy and the repeatability of data. All experiments were separately repeated triplicate. Data were analysed using descriptive statistics (standard deviation and variance) and one-way ANOVA for assessing the significance of differences. A value of $p<0.05$ was taken as significantly different.

\section{Results}

\subsection{Identification of chemical compounds in SAEO}

The py-GC/MS chromatogram revealed that SAEO contained twelve chemical compounds with eugenol $(22.1 \%)$ and aceteugenol $(13.31 \%)$ as the major essential oils (Figure 1 and Table 1). SAEO had approximately $45.76 \%$ essential oils classified in phenylpropanoid and sesquiterpenoid groups.

Table 1. Identification of chemical compounds in S. aromaticum essential oil

\begin{tabular}{|c|c|c|c|c|}
\hline Peak & Retention time & Compounds & Concentration (\%) & Group \\
\hline 1 & 2.677 & Propanethiol & 52.17 & Thiol \\
\hline 2 & 15.708 & Trans anethole & 2.16 & Phenylpropanoid \\
\hline 3 & 16.466 & Eugenol & 22.1 & Phenylpropanoid \\
\hline 4 & 16.617 & Alpha-copaene & 0.36 & Sesquiterpenoid \\
\hline 5 & 17.094 & Trans-caryophyllene & 6.48 & Sesquiterpenoid \\
\hline 6 & 17.391 & Alpha-humulene & 0.71 & Sesquiterpenoid \\
\hline 7 & 17.846 & Aceteugenol & 13.31 & Phenylpropanoid \\
\hline 8 & 18.557 & Caryophyllene oxide & 0.64 & Sesquiterpenoid \\
\hline 9 & 18.958 & Tetracyclo [6.3.2.0E2,5.0E1,8] tridecan-9-ol, 4,4-dimetyl & 0.42 & Alkane \\
\hline 10 & 19.291 & 2',3',4' Trimethoxyacetophenone & 0.59 & Ketone \\
\hline 11 & 20.897 & Palmitic acid & 0.54 & Fatty acid \\
\hline 12 & 22.164 & Linoleic acid & 0.52 & Fatty acid \\
\hline
\end{tabular}




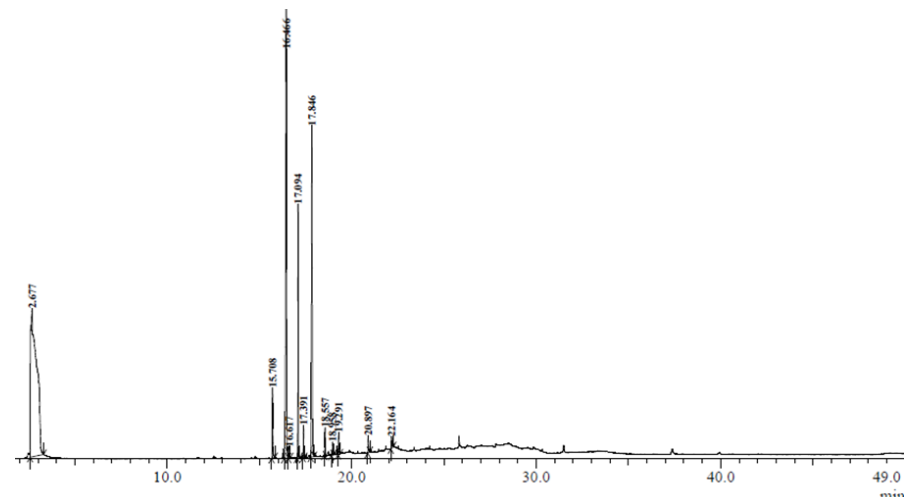

Figure 1. Identification of chemical components in $S$. aromaticum essential oil by py-GC/MS.

\subsection{Effect of SAEO against $S$. sanguinis biofilm} formation and eradication

Figure 2a demonstrated the effect of SAEO at various doses on preventing the formation of $S$. sanguinis biofilm. SAEO at $60 \mu \mathrm{g} / \mathrm{mL}$ effectively inhibited S. sanguinis formation up to $50 \%$ as well as chlorhexidine reference. However, the inhibition pattern was not dose-dependent manner. SAEO was also tested on killing the existed $S$. sanguinis biofilm (Figure $2 b$ ). At $40 \mu \mathrm{g} / \mathrm{ml}$, SAEO removed effectively up to $50 \%$ of the existed $S$. sanguinis biofilm, and its efficacy was similar to the chlorhexidine reference.
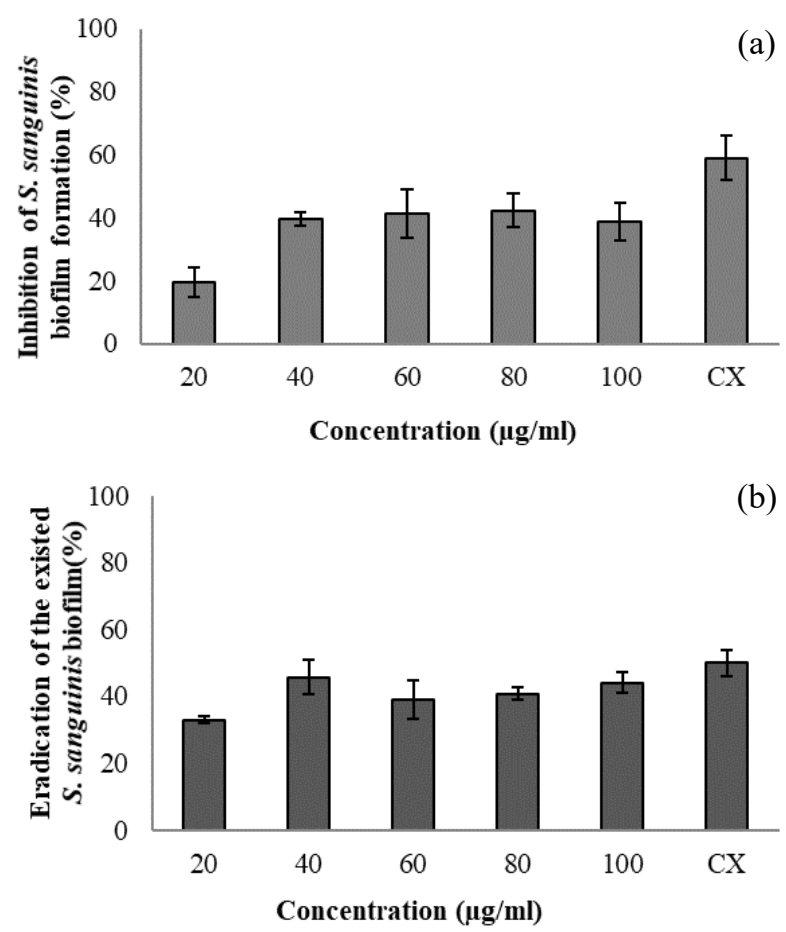

Figure 2. Effect of $S$. aromaticum essential oil on preventing $S$. sanguinis biofilm formation (a) and eradicating the existed $S$. sanguinis biofilms (b). CX, chlorhexidine reference.

\subsection{Effect of SAEO on VSCs production inhibition}

Oral bacteria $S$. sanguinis increased the VSCs production and SAEO was further tested whether it reduced the VSCs. Our results showed that SAEO at 20$80 \mu \mathrm{g} / \mathrm{mL}$ exerted dose-dependent pattern on inhibiting
VSCs produced by $S$. sanguinis (Figure 3). At $60 \mu \mathrm{g} /$ $\mathrm{mL}$, SAEO significantly decreased the total VSCs $>50 \%$.

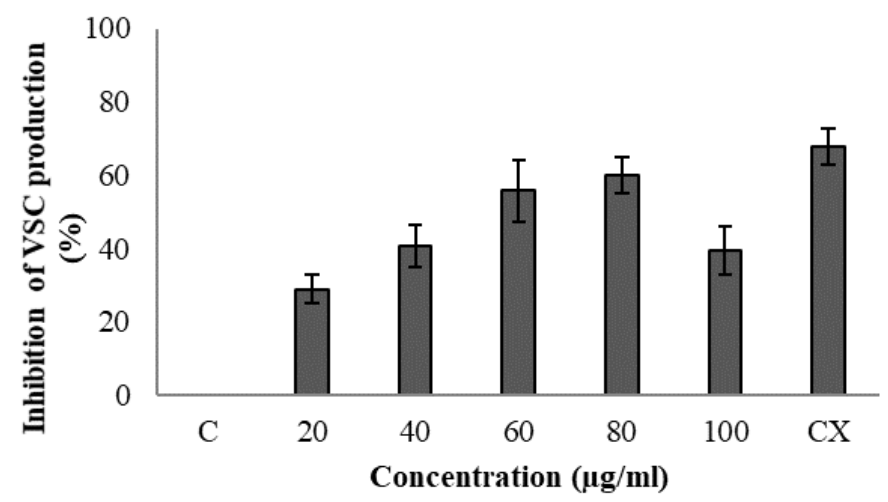

Figure 3. Effect of $S$. aromaticum essential oil on inhibiting volatile sulphur compound production. $\mathrm{C}$, negative control; $\mathrm{CX}$, chlorhexidine reference; $\mathrm{p}<0.05$ against negative control.

\subsection{Effect of SAEO on acid production inhibition}

Figure 4 demonstrated that the production of acid by S. sanguinis increased during 0-20 mins, indicating by the decrease of $\mathrm{pH}$ value. SAEO effectively inhibited $S$. sanguinis acid production by reducing the terminal $\mathrm{pH}$ value compared to that of negative control (Figure 4a). The terminal $\mathrm{pH}$ value of negative control $\mathrm{pH}$ was reduced until 5.66. After treatment with SAEO at $60 \mu \mathrm{g} /$ $\mathrm{mL}$, the terminal $\mathrm{pH}$ value increased up to 6.3. Its efficacy was similar to chlorhexidine reference which raised the terminal $\mathrm{pH}$ value until 6.53. SAEO also decreased acid production rate (Figure $4 \mathrm{~b}$ ). At higher concentration $(60-100 \mu \mathrm{g} / \mathrm{mL})$, SAEO showed a similar inhibition pattern with chlorhexidine reference on acid produced by S. sanguinis.
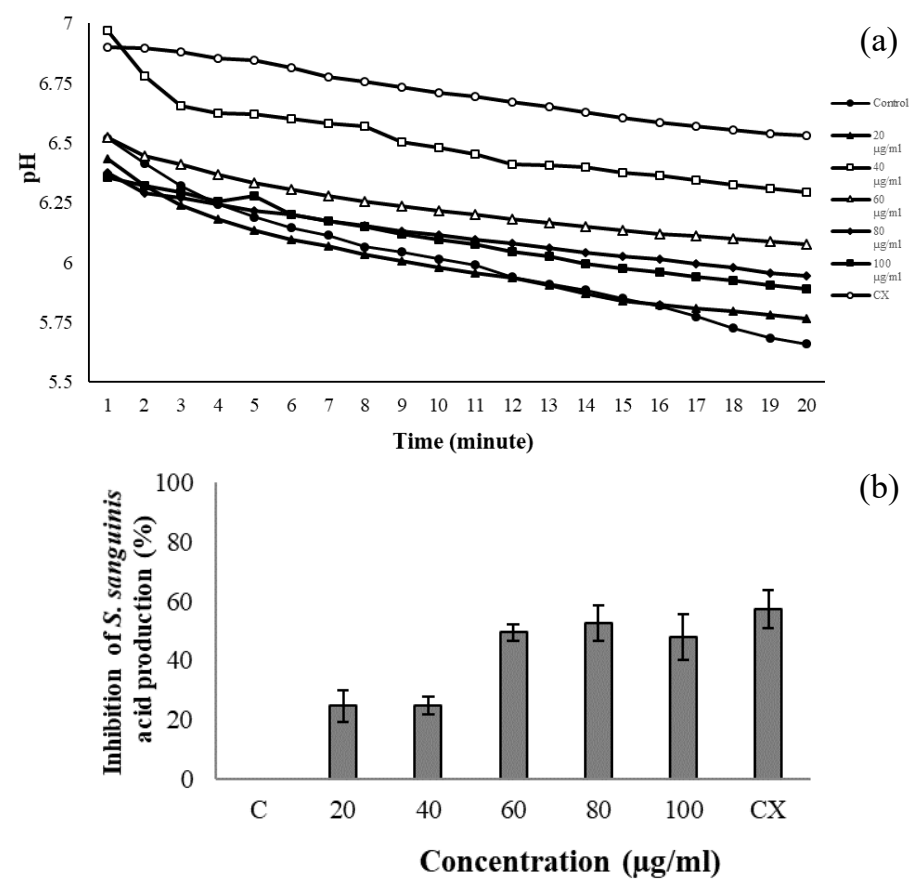

Figure 4. Effect of $S$. aromaticum essential oil on decreasing the $\mathrm{pH}$ value (a) and inhibiting acid produced by $S$. sanguinis (b). C, negative control; $\mathrm{CX}$, chlorhexidine reference; $\mathrm{p}<0.05$ against negative control. 


\section{Discussion}

S. aromaticum has been widely used as a traditional medicine for the treatment of oral-related diseases and may be applied for a more specific target in oral diseases particularly halitosis. In this study, it was observed that SAEO had a strong inhibitory effect towards $S$. sanguinis ability to produce biofilms, total acid and VSCs (Figures 2-4). The py-GC/MS result showed that SAEO contained major active compounds, including eugenol and aceteugenol which have health benefits (Figure 1 and Table 1). Eugenol was known to have anti-inflammatory, antimutagen, and antimicrobial broad-spectrum activities (Rahim and Khan, 2006). Terpenoids contained in SAEO also has been reported to have antimicrobial activity towards bacteria and fungi (Ndam et al., 2016). Fatty acids (palmitic acid and linoleic acid) contained in SAEO also possess antimicrobial activity and play an important role in the cellular process (Abdullah, 2013). Long chain fatty acids also have been reported to have a strong antimicrobial effect towards $S$. sanguinis (Huang et al., 2011).

In terms of its antibiofilm efficacy against $S$. sanguinis biofilms (Figure 2a), SAEO may inhibit the biofilm formation of $S$. sanguinis by affecting initial attachment and glucan synthesis. Rahim and Khan (2006) had reported $S$. aromaticum methanol extract had an inhibitory effect towards $S$. mutans initial attachment to glass surface, but the effect was not caused by eugenol antimicrobial activity. Eugenol was also known to affect the ATP ion channel and change the fatty acid profile of bacteria by altering the membrane (Nazzaro et al., 2013). More research is needed to uncover the active component responsible for initial attachment inhibition. Glucan synthesis inhibition may be resulted from eugenol capability to alter the membranes which affect the cell membrane permeability towards primary component to produce energy and biofilm (Gill et al., 2004).

Biofilm eradication result showed that SAEO had stronger eradication ability than chlorhexidine reference (Figure 2b). The result may be caused by the difference in lower molecular weight of SAEO active compounds compared to the molecular weight of chlorhexidine reference $(505 \mathrm{~g} / \mathrm{mol})$. SAEO with lower molecular weight $(115 \mathrm{~g} / \mathrm{mol})$ had a better penetration ability towards the existed biofilm (Peterson et al., 2015). These existed biofilms are more resistant to the antimicrobial agent that was proved in chlorhexidine reference $(20 \mu \mathrm{g} /$ $\mathrm{mL}$ ). Based on Figure 2, chlorhexidine showed the inability to eradicate $S$. sanguinis biofilm than to prevent the biofilm formation. Antimicrobial activity may reduce the total viable cell within the biofilm, therefore reduce the biofilm integrity (Steinberg et al., 2004). However, further study could be specifically designed to examine the penetration ability in a more mature biofilm.

VSCs produced by $S$. sanguinis from the degradation of enzyme-containing sulphur. Inhibition of VSCs production by SAEO indicated its potential ability to treat halitosis (Figure 3). The reduction of VSCs production may be caused by eugenol ability to decrease the total viable cells. Inhibition towards VSCs-producing enzyme could not be observed in this research. Specific research is needed to observe the SAEO ability towards VSCs-producing enzyme inhibition and a further characterization and sample purification may be needed to identify the responsible compounds. VSCs production involved several pathogenic bacteria (Kang et al., 2006), therefore, the use of consortium or in vivo treatment is a better option than using only single culture bacteria.

The acid produced by $S$. sanguinis also contributed for tooth demineralization (Percival et al., 2006). It was also observed that acid production of $S$. sanguinis was susceptible to SAEO and chlorhexidine. Our data showed that SAEO ability at higher concentration (60$100 \mu \mathrm{g} / \mathrm{mL}$ ) was comparable with chlorhexidine in inhibiting acid produced by $S$. sanguinis (Figure 4). It is known that acid production is strongly linked with energy production in $S$. sanguinis because compounds that could inhibit nutrient uptake and act as an inhibitor on nutrient metabolism enzyme may be used as potential caries reducing agent (Percival et al., 2006). Reduction of acid may be resulted in the antimicrobial activity of SAEO active compounds. Another study also stated that eugenol ability to damage the membrane play an important role in nutrient uptake and maintain cell integrity and lower the production of ATP in cells (Nazzaro et al. 2013).

\section{Conclusion}

SAEO contained major eugenol exerted potential anti-halitosis effect by preventing $S$. sanguinis biofilm formation, eradicating the existed $S$. sanguinis biofilms, inhibiting $S$. sanguinis VSCs production, and reducing $S$. sanguinis acid production. SAEO may be applied as a promising natural material in developing oral care functional products for management of halitosis.

\section{Conflict of Interest}

The authors declare no conflict interest. The authors alone are responsible for the content of the paper.

\section{Acknowledgement}

This study was funded by the Institute for Research and Community Service of Atma Jaya through 2015 
Atma Jaya Competitive Grant.

\section{References}

Abdullah, N.S. (2013). Fatty acids profiles of red seaweed Gracilaria manilaensis. The Experiment Journal, 11(5), 726-732.

Akkaoui, S. and Ennibi, O.K. (2017). Use of traditional plants in management of halitosis in a Moroccan population. Journal of Intercultural Ethnopharmacology, 6(3), 267-273. http:// dx.doi.org/10.5455/jice.20170522103525

Cord-Ruwisch, R. (1985). A quick method for the determination of dissolved and precipitated sulfides in cultures of sulfate-reducing bacteria. Journal of Microbiological Methods, 4(1), 33-36. https:// doi.org/10.1016/0167-7012(85)90005-3

Duarte, S., Gregoire, S., Singh, A.P., Vorsa, N., Schaich, K., Bowen, W.H. and Koo, H. (2006). Inhibitory effects of cranberry polyphenols on formation and acidogenicity of Streptococcus mutans biofilms. FEMS Microbiology Letters, 257(1), 50-56. https:// doi.org/10.1111/j.1574-6968.2006.00147.x

Fahimi, Sh. and Naseri, M. (2015). Anti-halitosis plants in Iranian traditional medicine. Research Journal of Pharmacognosy, 2(2), 61-66.

Gill, A.O. and Holley, R.A. (2004). Mechanisms of bactericidal action of cinnamaldehyde against Listeria monocytogenes and of eugenol against L. monocytogenes and Lactobacillus sakei. Applied and Environmental Microbiology, 70 (10), 5750-5755. http://dx.doi.org/10.1128/ AEM.70.10.5750-5755.2004

Guan, W., Li S., Yan, R., Tang, S. and Quan, C. (2007). Comparison of essentials oils of clove buds extracted with supercritical carbon dioxide and other three traditional extraction methods. Food Chemistry, 101 (4), 1558-1564. http://dx.doi.org/10.1016/ j.foodchem.2006.04.009

Huang, C.B., Altimova, Y., Myers, T.M. and Ebersole, J.L. (2011). Short- and medium-chain fatty acids exhibit antimicrobial activity for oral microorganisms. Archives of Oral Biology, 56(7), 650-654.

j.archoralbio.2011.01.011

Kang, M.S., Kim, B.G., Chung, J., Lee, H.C. and Oh, J.S. (2006). Inhibitory effect of Weisella cibaria isolates on the production of volatile sulphur compounds. Journal of Clinical Periodontology, 33 (3), 226-232. https://doi.org/10.1111/j.1600051X.2006.00893.x

Kaur, D. and Chandrul, K.K. (2017). Syzygium aromaticum L. (Clove): A vital herbal drug used in periodontal disease. Indian Journal of Pharmaceutical and Biological Research, 5(2), 4551. http://dx.doi.org/10.30750/ijpbr.5.2.9

Kreth, J., Meritt, J., Shi, W. and Qi, F. (2005). Competition and coexistence between Streptococcus mutans and Streptococcus sanguinis in the dental biofilm. Journal of Bacteriology, 187(21), 71937203. http://dx.doi.org/10.1128/JB.187.21.71937203.2005

Marawar, P.P., Sodhi, N.A., Pawar, B.R. and Mani, A.M. (2012). Halitosis: A silent affliction. Chronicles of Young Scientists, 3(4), 251-257. http:// dx.doi.org/10.4103/2229-5186.103091

Nazzaro, F., Fratianni, F., De Martino, L., Coppola, R. and De Feo, V. (2013). Effect of essential oils on pathogenic bacteria. Pharmaceuticals (Basel), 6(12), 1451-1474. http://dx.doi.org/10.3390/ph6121451

Ndam, L.M., Mih, A.M., Tening, A.S., Fongod, A.N, Temenu, N.A. and Fujii, Y. (2016). Phytochemical analysis, antimicrobial and antioxidant activities of Euphorbia golondrina L.C. Wheeler (Euphorbiaceae Juss.): an unexplored medicinal herb reported from Cameroon. Springerplus, 5, 264. doi: 10.1186/s40064-016-1928-8.

Paes Leme, A.F., Koo, H., Bellato, C.M., Bedi, G. and Cury, J.A. (2008). The role of sucrose in cariogenic dental biofilm formation-new insight. Journal of Dental Research, 85(10), 878-887. https:// doi.org/10.1177/154405910608501002

Pal, D., Banerjee, S., Mukherjee, S., Roy, A., Panda, C.K. and Das, S. (2010). Eugenol restricts DMBA croton oil induced skin carcinogenesis in mice: down regulation of c-Myc and $\mathrm{H}-$ ras, and activation of $\mathrm{p} 53$ dependent apoptotic pathway. Journal of Dermatological Science, 59(1), 31-9. http:// dx.doi.org/10.1016/j.jdermsci.2010.04.013

Percival, R.S., Devine, D.A., Duggal, M.S., Charton, S. and Marsh, P.D. (2006). The effect of cocoa polyphenols on the growth, metabolism, and biofilm formation by Streptococcus mutans and Streptococcus sanguinis. European Journal of Oral Sciences, 114(5), 343-348. http://dx.doi.org/10.1111/ j.1600-0722.2006.00386.x

Peterson, B.W., He, Y., Ren, Y., Zerdoum, A., Libera, M.R., Sharma, P.K., van Winkelhoff, A.J., Neut, D., Stoodley, P., van der Mei, H.C. and Busscher, H.J. (2015). Viscoelasticity of biofilms and their recalcitrance to mechanical and chemical challenges. FEMS Microbiology Reviews, 39(2), 234-245. http:// dx.doi.org/10.1093/femsre/fuu008

Pulikottil, S.J. and Nath, S. (2015). Potential of clove of Syzygium aromaticum in development of a 
therapeutic agent for periodontal disease: A review. The South African Dental Journal, 70(3), 108-115.

Rahim, Z.H. and Khan, H.B. (2006). Comparative studies on the effect of crude aqueous and solvent extracts of clove on the cariogenic properties of Streptococcus mutans. Journal of Oral Science, 48 (3), 117-123. http://dx.doi.org/10.2334/ josnusd.48.117

Steinberg, D., Feldman, M., Ofek, I. and Weiss, E.I. (2004). Effect of a high-molecular-weight component of cranberry on constituents of dental biofilm. Journal of Antimicrobial Chemotherapy, 54 (1), 86-89. http://dx.doi.org/10.1093/jac/dkh254

Thorn, R.M. and John, G. (2012). Microbial volatile compounds in health and disease conditions. Journal of Breath Research, 6(2), 24001-24025. http:// dx.doi.org/10.1088/1752-7155/6/2/024001

Yamaguchi, M., Terao, Y., Ogawa, T., Takahashi, T., Hamada, S. and Kawabata, S. (2006). Role of Streptococcus sanguinis sortase A in bacterial colonization. Microbes and Infection, 8(12-13), 2791 -2796 . http://dx.doi.org/10.1016/ j.micinf.2006.08.010

Yanti, Rukayadi, Y., Lee, K.H. and Hwang, J.K. (2009). Activity of panduratin A isolated from Kaempferia pandurata Roxb. against multi-species oral biofilms in vitro. Journal of Oral Science, 51(1), 87-95. http://dx.doi.org/10.2334/josnusd.51.87 